\title{
ROC Analysis on SRED-7F Instrument (Study: Development of a New Instrument of Clinical Psychology)
}

\author{
Siti Bahiyah ${ }^{1}$ Samsunuwiyati Marat ${ }^{1}$ Rita Markus Idulfilastri ${ }^{1 *}$ \\ ${ }^{1}$ Faculty of Psychology, Universitas Tarumanagara, Jakarta 11470, Indonesia \\ "Corresponding author. Email: ritamarkus@fpsi.untar.ac.id
}

\begin{abstract}
The typical psychological change in adolescents of increased emotional intensity coupled with a lack of cognitive resources is one theoretical explanation for the increase in depression during adolescence. Adolescents seek to increase self-understanding and seek identity in relationships with family and friends, but can develop problems such as juvenile delinquency and depression. DSM 5 defines depression as a mood disorder in which a person is overwhelmed by feelings of sadness, emptiness, and hopelessness or loses interest in various activities for two weeks or more. SRED-7F (Emotion Regulation Strategy of Symptom Depresson7 Factors) is a new screening instrument for clinical psychology. Therefore, it is necessary to know the level of sensitivity to specificity at all possible thresholds using Receiver Operating Characteristic (ROC) analysis. The characteristics of the participants were middle adolescents and the sample was taken using purposive sampling. The number of participants was 493 students from 4 public high schools and 1 public vocational school in Jakarta. The conclusion that the prevalence of depression was $61.7 \%$ or 304 of the 493 adolescents in this study showed symptoms of depression. The Adaptive subtest cut-off score at a score of 108 from the highest score of 155 and the Maladaptive subtest cut-off score at a score of 29 from the highest score of 45. SRED-7F has a sensitivity and specificity ranging from $50 \%$ to $70 \%$ indicating that the SRED-7F can detect adolescents with depressive symptoms and adolescents who do not show depressive symptoms.
\end{abstract}

Keywords: Adolescence, emotional regulation strategy, ROC

\section{INTRODUCTION}

Adolescence is marked by the physical maturation of the brain and body which causes intense psychological and physical changes, typical psychological changes of adolescence, including the intensification of emotional experiences [1]. The development of adolescence strengthens the understanding as a critical or sensitive period for the reorganization of the regulatory system that is full of opportunities and risks [2]. Emotional experiences when dealing with affective situations often result in an increase in emotional responses, even though adolescents have better emotional awareness than childhood but in general adolescent control functions are inadequate [3]. Adolescents experience stronger emotional intensity, but may not have the cognitive resources to cope with these emotions, especially in an interpersonal context [4]. The pattern of increased emotional intensity coupled with a lack of cognitive resources, is one theoretical explanation for the increase in depression during adolescence [5].

Daily affective experiences in adolescents can contribute to differences in depression risk [4]. The picture of the social world that teenagers encounter illustrates how complicated their world is. Individual friendship relationships become more intimate and trusting, and the addition of romantic relationships during adolescence [5]. Adolescents are trapped in more complex social structures that lead to instability and require the development of new skills that are important to direct them, and this requires more effort [5]. Adolescents try to adjust, but some of them experience instability as a consequence of adjusting. Adolescents seek to increase self-understanding and the search for identity that takes place in relationships with family and peers in a cultural context that can develop problems such as juvenile delinquency and depression [6].

\subsection{Related Work}

DSM 5 defines depression as a mood disorder in which a person is overwhelmed by feelings of sadness, emptiness, and hopelessness or loses interest in various activities for two weeks or more [7]. Signs of depression in adolescents, such as mood swings or loss of interest in all activities, and adolescents who experience depression will look sad, unhappy, fussy, complaining, irritable, and irritable [8] Several factors can put adolescents at risk for depression, 
such as parents who suffer from depression, the absence of emotional attachment to parents, parental marital conflicts and financial problems. Bad relationships with peers can also lead to depression, such as not having close friends, lack of contact with friends, experiencing rejection from peers, as well as romantic relationships that can trigger depression, especially in young girls [6].

Emotion regulation includes conscious and automatic regulation of emotions that arise in everyday life or in response to stressors. Regulation can be internal by yourself or set externally by others. Success in emotional regulation is a central aspect of psychosocial functioning and mental health and is considered to be increased and perfected in adolescence [9]. In contrast, adolescents with low emotional regulation can experience various forms of psychopathology, both from internal and external disorders. Referring to the review of Meta-analysis of Emotional Regulation Across Psychopathology, measuring emotional regulation strategies that have been used using 4 instruments in the sample shows depression symptom with 8 emotional regulation strategies. Given the large number of instruments used and can increase the error in the assessment results, an instrument called the SRED- 7F (Emotional Regulation Strategy of Symptom Depression 7 Factors) was created.

\subsection{Our Contribution}

The SRED-7F is an instrument that measures 7 depressive symptoms in adolescents in one measuring device. The SRED-7F is a new instrument in the context of clinical psychology, because it is necessary to test the accuracy and accuracy using the Receiver Operating Characteristic (ROC) curve analysis. ROC is a method for evaluating the accuracy of various predictions [10]. With the ROC curve it can be seen the level of sensitivity to specificity at all possible thresholds. The sensitivity and specificity of measuring instruments are trade-offs and their relationship characteristics are described in the Receiver Operating Characteristic Curve (ROC). In other words, the aim of this study was to analyze the SRED-7F instrument at the level of sensitivity and specificity using the ROC.

\subsection{Paper Structure}

The paper is organised as follows. Section 2 served as methods section, which include the characteristics of research participants, measures used, and the description of how the data will be analysed. Section 3 consists of statistical analysis result of ROC and discussion of the result. In Section 4, we conclude the paper and suggestion for future research.

\section{METHODS}

\subsection{Participants}

The population characteristics are high school and vocational high school students who are categorized as middle adolescents. The sampling technique was purposive sampling and obtained a total sample size of 493 students from 4 State Senior High Schools and 1 State Vocational High School and each school representing each area of Jakarta. Based on the total sample size of the North Jakarta area of 97 students (19.7\%), East Jakarta 96 students (19.5), South Jakarta 100 students (20.35), Central Jakarta 105 students (21.3\%) and West Jakarta 95 students (19.3\%).

\subsection{SERD-7F (Emotion Regulation Strategies of Emotion Symptom - 7 Factors)}

The SRED-7F is a psychological instrument used for screening in clinical settings. The SRED-7F is built on 7 factors and 40 points (31 favourable and 9 unfavourable items). The SRED-7F consists of 2 regulatory subscales, namely positive emotion regulation and negative emotion regulation. Adaptive emotion regulation consists of 5 factors, namely problem solving, social support, reappraisal, distraction, and pleasant, and regulation of maladaptive emotions consists of 2 factors, namely avoidance and rumination factors. In the instrument format, it is classified into 4 sections, namely part 1 consisting of 19 statements about strategies to overcome stressors. Example items: "I consider options very carefully"; Part 2 consists of 4 questions about emotional life specifically controlling emotions. Example items: "I control my emotions by thinking about the situation I am in"; Section 3 consists of 8 responses to feelings of depression. Example items: "Thinking how difficult it is to construct"; Section 4 consists of 9 statements about feeling yourself. Example item: "I receive pleasant feelings. Respondents' responses consisted of 5 categories, namely (1) never, (2) rarely; (3) sometimes; (4) often; (5) very often.

\subsection{Analysis Technique}

Analysis using ROC (Receiver Operating Characteristic). Psychological assessment explains that accuracy consists of two things, namely sensitivity and specificity. [11] defines sensitivity as the proportion of the number of people who have the disorder or have a positive test result. Meanwhile, specificity is defined as the proportion of the number of people who are not impaired or have negative test results. In addition to sensitivity and specificity, there are terms of positive predictive value and negative predictive value. The positive predictive value refers to how much the positive results given by the instrument are truly positive, while the negative predictive value refers to how much negative results given by the instrument are truly negative [12]. 
Analysis using ROC (Receiver Operating Characteristic). Psychological assessment explains that accuracy consists of two things, namely sensitivity and specificity. [11] defines sensitivity as the proportion of the number of people who have the disorder or have a positive test result. Meanwhile, specificity is defined as the proportion of the number of people who are not impaired or have negative test results.
In addition to sensitivity and specificity, there are terms of positive predictive value and negative predictive value. The positive predictive value refers to how much the positive results given by the instrument are truly positive, while the negative predictive value refers to how negative the negative results given by the instrument are truly negative [12]. See Table 1.

\section{Table 1 Standardized Results}

\begin{tabular}{lcc}
\hline Test Result & Positive Result & Negative Result \\
\hline Positive Result & A & B \\
& True Positive & False Positive \\
Negative Result & C & D \\
& True Positive \\
\hline Note: Cutoff Value indicates the criterion value range that predicts a positive \\
condition. \\
A is the number of True Positives; B is the number of False Positives; C is the \\
number of False Negatives. D is the number of True Negatives; \\
TPR is the True Positive Rate or Sensitivity = A / $(\mathrm{A}+\mathrm{C})$. \\
TNR is the True Negative Rate or Specificity = D / (B + D).
\end{tabular}

In practice, there is a trade-off between sensitivity and specificity values, based on the intended use of the instrument being tested. The higher the sensitivity value, the lower the specificity value, and vice versa. It is this tradeoff between the sensitivity at various intersection points which is then reflected in the ROC curve [12]. Furthermore, the instrument user must make a trade-off between the sensitivity and specificity of the instrument [11], and this bargain is usually used as a clinical consideration when determining the point of cut. optimum scoring psychodiagnostic instrument. [13] Warner states that an ideal instrument would have one intersection point with a sensitivity value of $1(100 \%$ succeeded in identifying the real case) and a specificity value of 1 (100\% succeeded in excluding negative cases). In fact, instruments with a sensitivity and specificity value of 1 are difficult to find, and clinicians need to make a bargain between the sensitivity and specificity values according to the needs of the instrument. In addition to the optimal cutoff value, ROC analysis can also produce an Area Under The AUC value, namely the number of examinations that produce correct conclusions in determining the presence or absence of interference. The AUC value ranges from $50 \%(0.5)$ to
$100 \%$ (1). The AUC value of $50 \%$ is the worst AUC value, while the AUC value of $100 \%$ is the best value [12].

\section{RESULT AND DISCUSSION}

The results of comparing the emotional regulation score with the CESD-R scale (Central for Epidemiology Studies Depression-Revision) obtained information on the prevalence of depression estimation of $61.7 \%$ or 304 out of 493 adolescents in this study showing symptoms of depression. The cutoff value for each dimension can be seen in table 2. The adaptive subtest has a cutoff of 108 from the highest score of 155 . This score limit is in the position of $70 \%$ of the highest score. If you get a score below 108 then it is said to have a low adaptive emotional regulation strategy, and vice versa. The maladaptive subtest has a cutoff of 29 from the highest score of 45 . This score limit is in the position of $64 \%$ of the highest score. If students get a score below a score of 29 , then it can be said that they have a low maladaptive emotional regulation strategy and vice versa. The results of these two scores will describe the emotional strategy holistically by considering the cut-off on a score of 7 factors. 
Table 2 ROC Results of Adolescent Emotion Regulation Scores

\begin{tabular}{lcccccccc}
\multicolumn{1}{c}{ Factors } & Cutoff & TPs & FPs & FNs & TNs & TPR & TNR \\
\cline { 2 - 8 } & Value & A & B & C & D & Sensitivity & Specificity \\
\hline Problem Solving & $\leq 27.00$ & 156 & 85 & 148 & 104 & 0.513 & 0.550 \\
Social Support & $\leq 20.00$ & 154 & 90 & 150 & 99 & 0.507 & 0.524 \\
Reappraisal & $\leq 13.00$ & 169 & 98 & 135 & 91 & 0.556 & 0.482 \\
Destruction & $\leq 11.00$ & 164 & 83 & 140 & 106 & 0.540 & 0.561 \\
Pleasant & $\leq 35.00$ & 158 & 92 & 146 & 97 & 0.520 & 0.513 \\
Adaptive Subtest & $\leq 108.00$ & 160 & 92 & 144 & 97 & 0.526 & 0.513 \\
Avoidance & $\leq 13.00$ & 189 & 56 & 115 & 133 & 0.622 & 0.704 \\
Rumination & $\leq 15.00$ & 214 & 65 & 90 & 124 & 0.704 & 0.656 \\
$\begin{array}{l}\text { Maladaptive } \\
\text { Subtest }\end{array}$ & $\leq 29.00$ & 214 & 60 & 90 & 129 & 0.704 & 0.683 \\
\hline & & & & & & &
\end{tabular}

In this study, to determine the clinical utility value of a measuring instrument for adolescent emotional regulation strategies with 7 factors of depression in detecting the presence of depression symptoms, researchers used ROC. Specifically, the researchers attempted to assess the performance of a measure of emotional regulation strategy for adolescents with 7-factor depression symptoms with limited access to the emotional regulation subscale score in detecting depression symptoms, by establishing a clinical cut-off score. The ROC curve is created when the true positive rate (sensitivity) intersects against the false positive (specificity). The results of the ROC analysis in this study are shown in Table 2 and Figure 1.

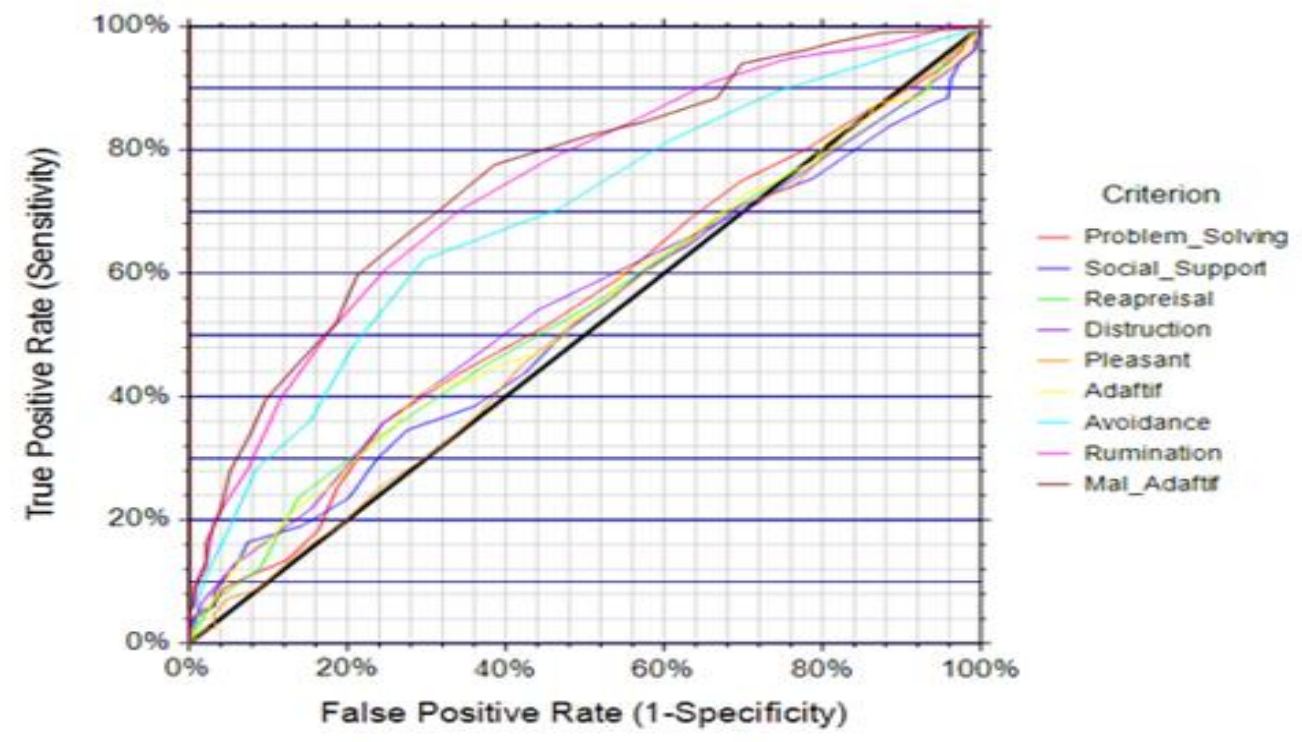

Figure 1 Depression Symptom - ROC Curve 


\section{CONCLUSION}

The prevalence of depression of $61.7 \%$ in this study indicated that the symptoms of depression were adequate for use in the screening assessment. SRED-7F has a sensitivity and specificity ranging from $50 \%$ to $70 \%$ indicating that SRED-7F can detect adolescents with depressive symptoms and who do not show depressive symptoms. The most distinguishing factor is avoidance and rumination. Both of these factors are the subtest maladaptive factors. Although sensitivity and specificity are the main indicators of screening and diagnostics in clinical psychology, they still have limitations in their applicative terms. The main limitation is that sensitivity and specificity are population-based measures, so that it will be difficult to apply in the interpretation of results for individual patients [11], [14].

\section{ACKNOWLEDGMENT}

Thank you for the facilities provided by Lembaga Penelitian dan Pengabdian kepada Masyarakat (LPPM) Universitas Tarumanagara for publication.

\section{REFERENCES}

[1] B. J. Casey et al., "The storm and stress of adolescence: Insights from human imaging and mouse genetics," Dev. Psychobiol., vol. 52, no. 3, pp. 225-235, 2010.

[2] L. Steinberg, "Cognitive and affective development in adolescence," Trends Cogn. Sci., vol. 9, no. 2, pp. 69$74,2005$.

[3] B. J. Casey, S. Getz, and A. Galvan, "The adolescent brain," Dev. Rev., vol. 28, no. 1, pp. 62-77, 2008.

[4] A. Frost, L. T. Hoyt, A. L. Chung, and E. K. Adam, "Daily life with depressive symptoms: Gender differences in adolescents' everyday emotional experiences," J. Adolesc., vol. 43, pp. 132-141, 2015.

[5] C. G. Davey, M. Yücel, and N. B. Allen, "The emergence of depression in adolescence: Development of the prefrontal cortex and the representation of reward," Neurosci. Biobehav. Rev., vol. 32, no. 1, pp. 119, 2008.

[6] Y. Sheen et al., "John Santrock-Life-Span Development-McGraw-Hill Education (2012).pdf," no. 4.

[7] S. Maya, "Strategi Peningkatan Penjualan Usaha Kecil Menegah Melalui E- Commerce Studi Kasus:
Mitra UKM Perusahaan X," JABE; J. Appl. Bus. Econ., vol. Vol.2, no. No.3, Maret 2016, pp. 271-279, 2016.

[8] A. Ramadhani and S. Retnowati, "Depresi Pada Remaja Korban Bullying," J. Psikol. UIN Sultan Syarif Kasim Riau, vol. 9, no. Desember, pp. 73-79, 2013.

[9] H. K. Lennarz, T. Hollenstein, A. LichtwarckAschoff, E. Kuntsche, and I. Granic, "Emotion regulation in action: Use, selection, and success of emotion regulation in adolescents' daily lives," Int. J. Behav. Dev., vol. 43, no. 1, pp. 1-11, 2019.

[10] M. Gönen, "NESUG 2006 Data Manipulation and Analysis Receiver Operating Characteristic ( ROC ) Curves Mithat Gönen , Memorial Sloan-Kettering Cancer Center NESUG 2006 Data Manipulation and Analysis FN + FP,” no. 2001, pp. 1-18, 2006.

[11] J. Attia, "Moving beyond sensitivity and specificity: Using likelihood ratios to help interpret diagnostic tests," Aust. Prescr., vol. 26, no. 5, pp. 111-113, 2003.

[12] Dahlan and M.S, Penelitian Diagnostik: Dasardasar Teoritis dan Aplikasi dengan Program SPSS dan Stata. Jakarta: Penerbit Salemba Medika, 2009.

[13] J. Warner, "Clinicians' Guide to Evaluating Diagnostika and Screening Test in Psychiatry," $J$. Contin. Prof. Dev., vol. 10, pp. 446-454, 2004.

[14] A. K. Akobeng, "Understanding diagnostic tests 3: Receiver operating characteristic curves," Acta Paediatr. Int. J. Paediatr., vol. 96, no. 5, pp. 644-647, 2007. 